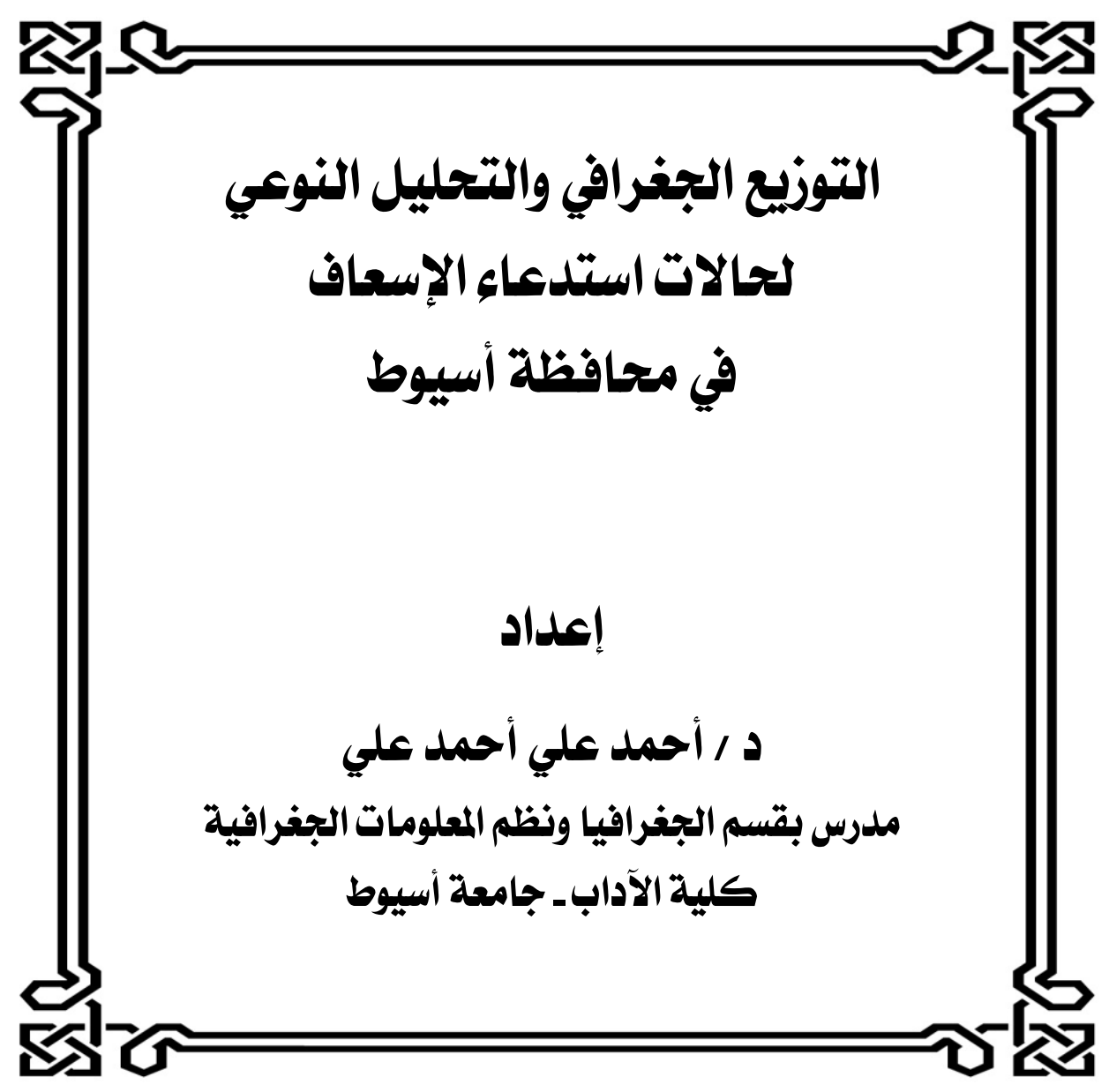





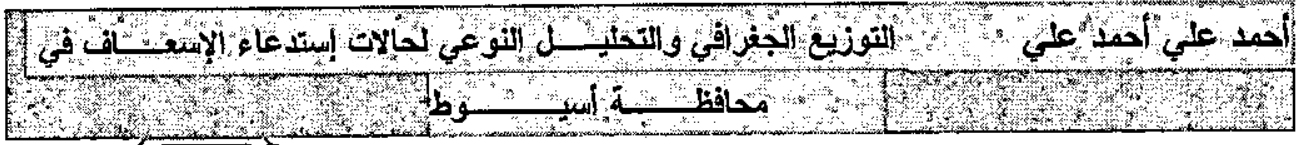

\section{$=$ \&1}

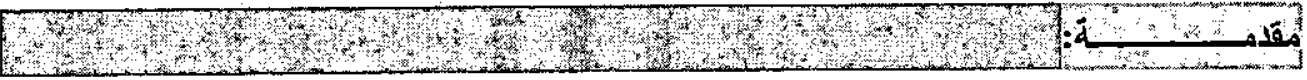

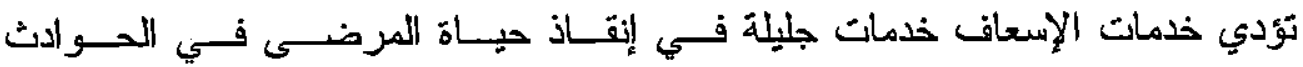

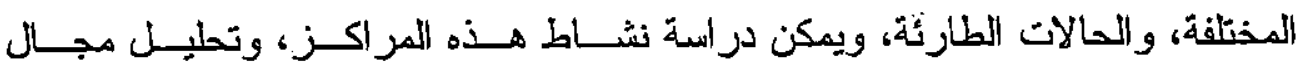

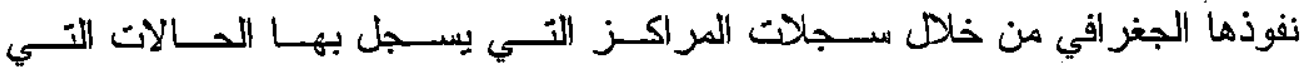

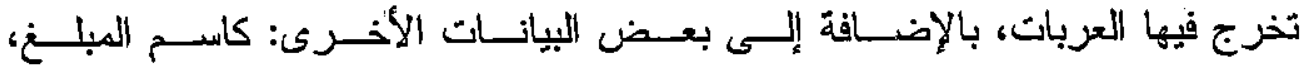

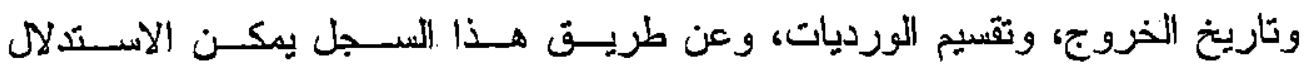

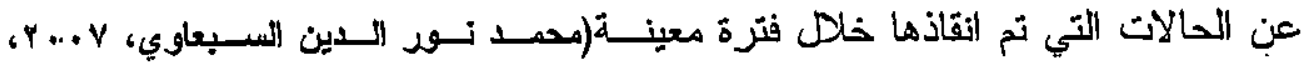

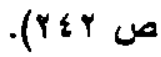

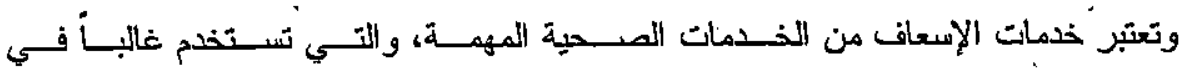

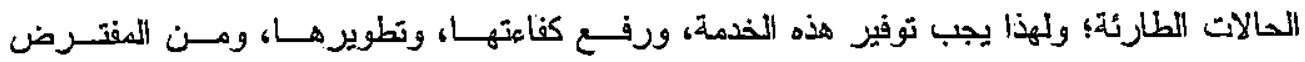

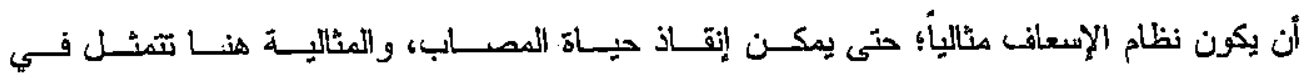

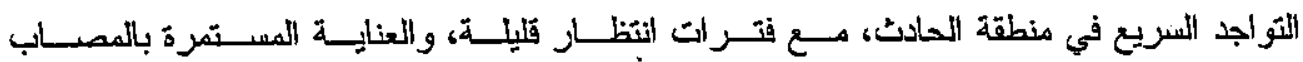
أنثاء نقله إلى المستشفى) (David, P, et al, 2014, P72).

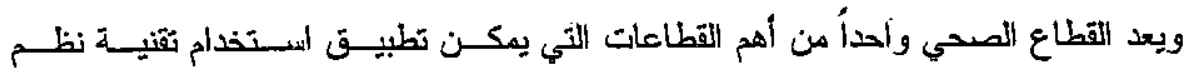

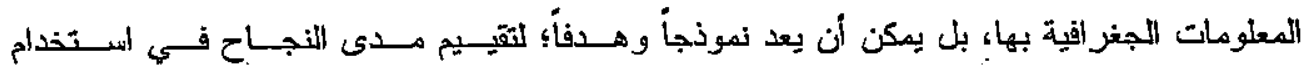

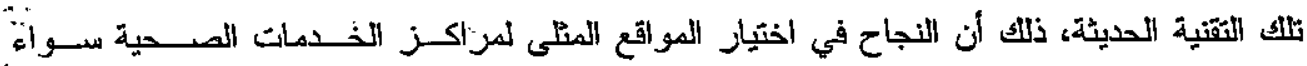

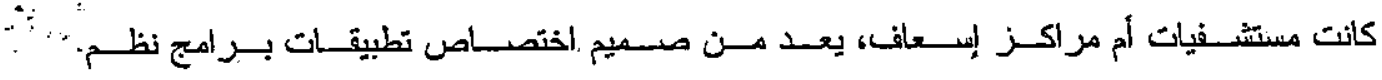

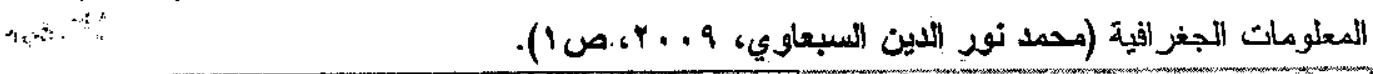

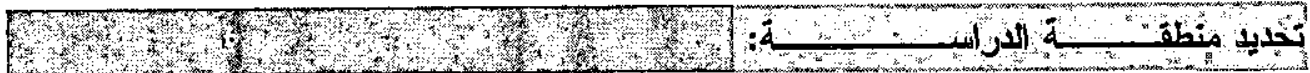

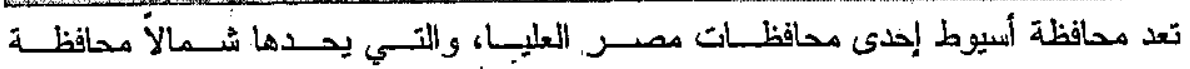

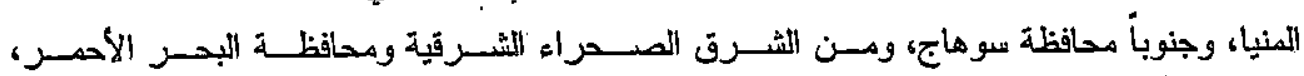

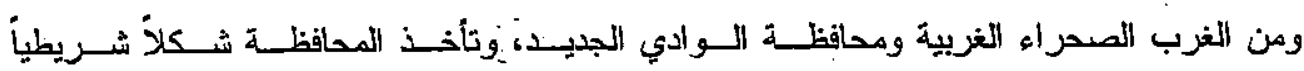
بطول • بأ كم على امتداد مجرى نهز الثيل. 


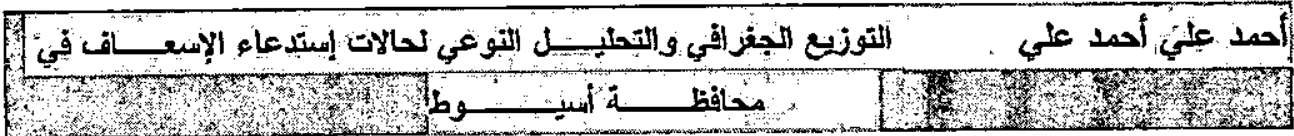
$=\frac{2 r}{0}$

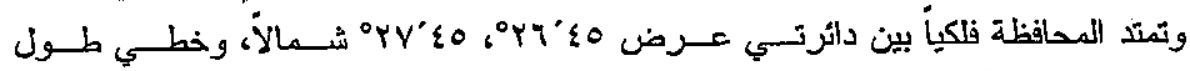

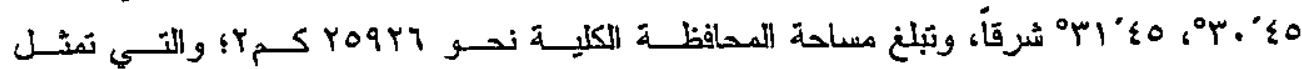

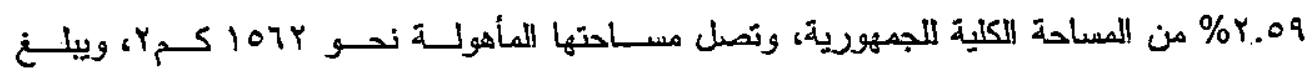
عدد سكانها نحو YIV

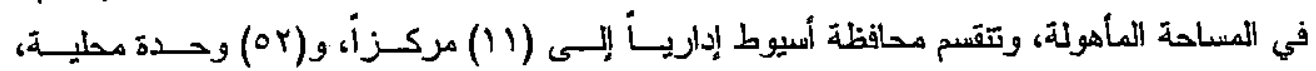

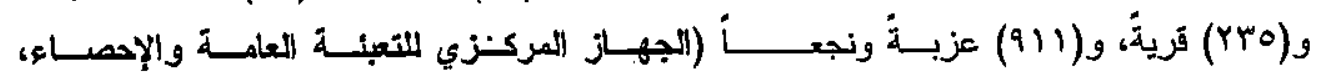

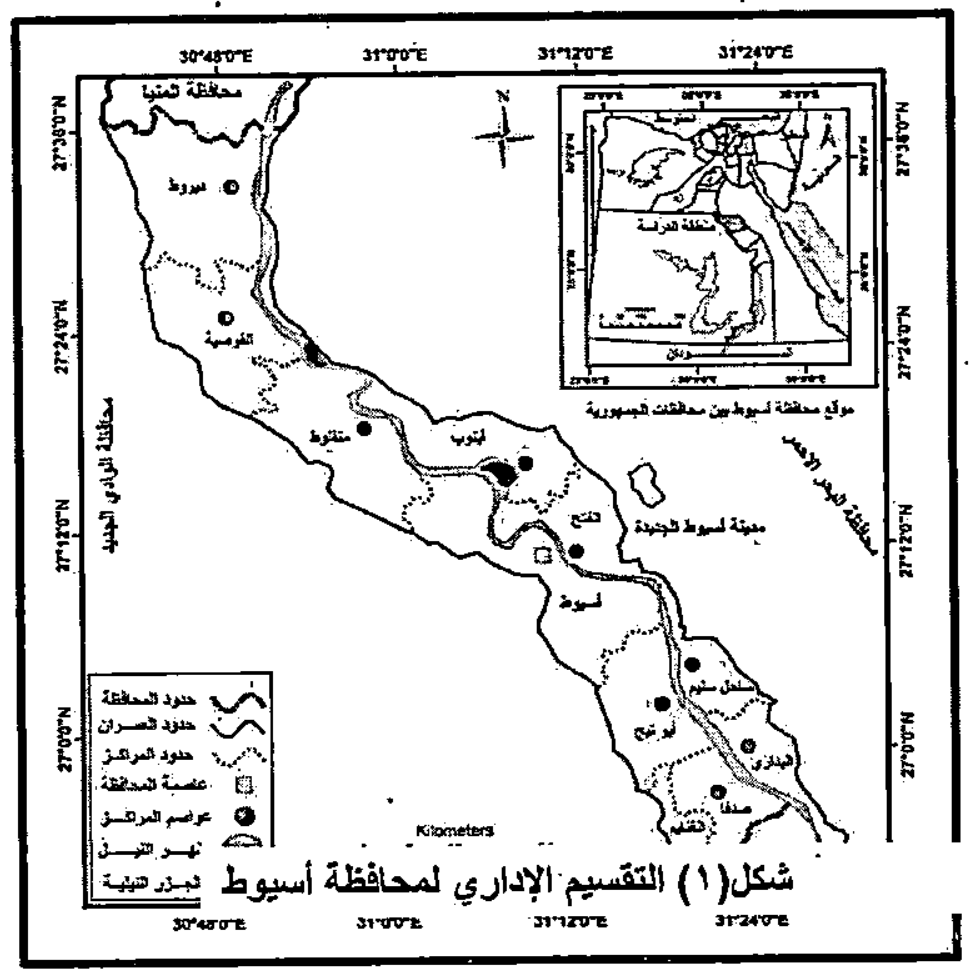




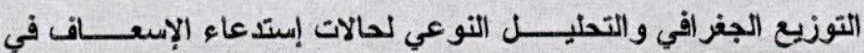

أحمد علي أحمد علي

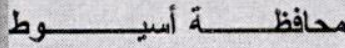

$=\frac{\pi}{2}$

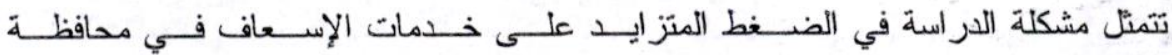

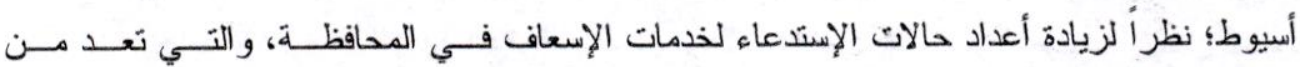

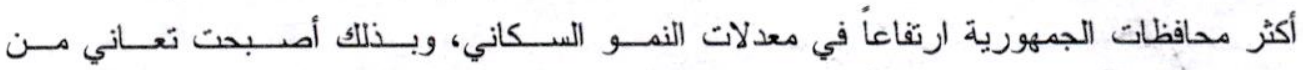

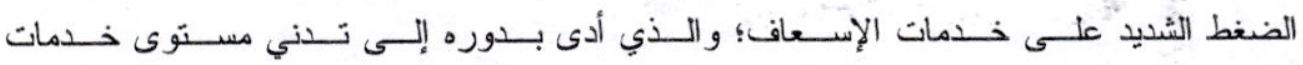
الإسعاف، وعدم كفايتها، وتتاسـبها مــع النـــو الســكاني، بالإضــافة إلــى بعـضـ الإثـــاليات

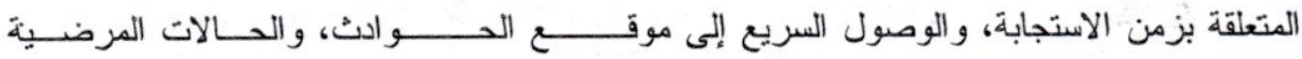
التي تسندعي خدمات الإسعاف.

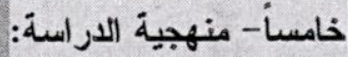

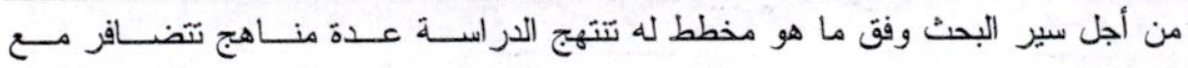
بعضها لتحقيق أهدافها، أهمه لــــــــــا:

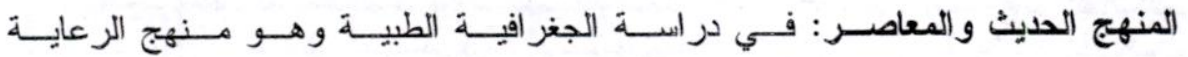

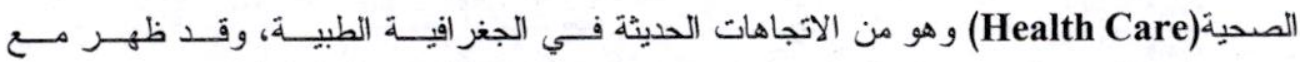

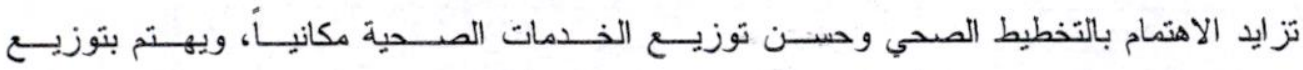
الخدمات الصحية في إقليم ما أو منطقة و التخطيط لها مستقبلاً.

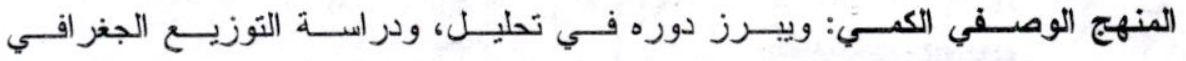
والتحليل النوعي و الزمني لحالات إستدعاء خدمات الإسعاف في محافظة أسيوط.

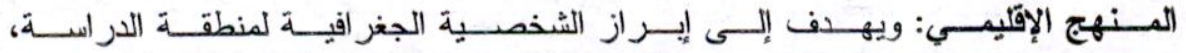

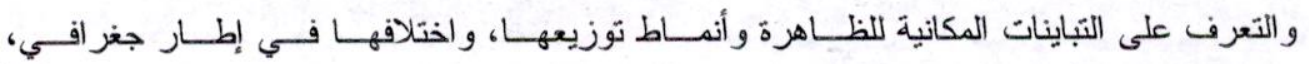
وتحليل كافة جو انبها، وتفاعلاتها المكانية.

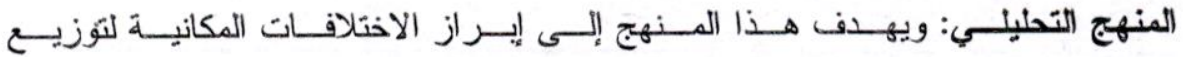

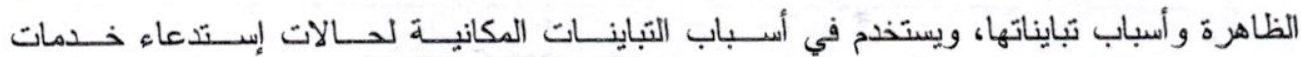
الإسعاف في محافظة أسيوط.

المنهج الاستقر ائي والاســتنباطي: ويظهر استخدام هذا المــنهج فــي تحليـلـ المؤشــرات المتعلقة بحالات إستدعاء خدمات الإسعاف على أساس البعد الزمني ؤ المكاني. 


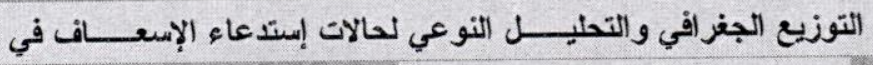

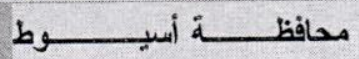

$=\frac{2 \varepsilon}{2}$

أولأ- التوزيع الجغر افي لحالات إستدعاء خدمات الإسعاف في محافظة أسبوط:

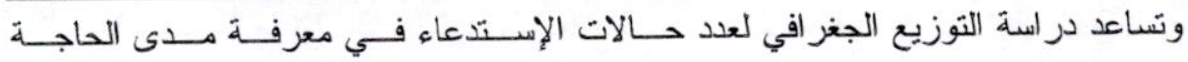

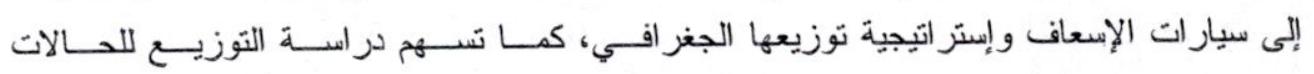

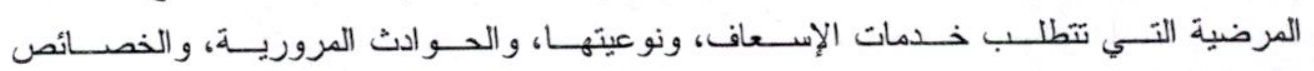
السكانية في توقع عدد الإستدعاءات، ونمــط الانتشــار المكـاني لذــدمات الإســعاف إ, Marcus

.(,et al,2008,p 145)

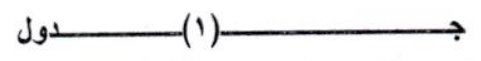

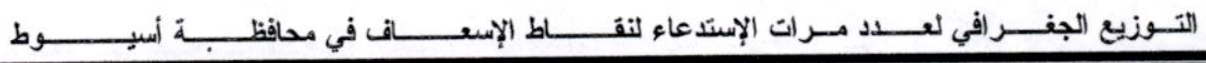

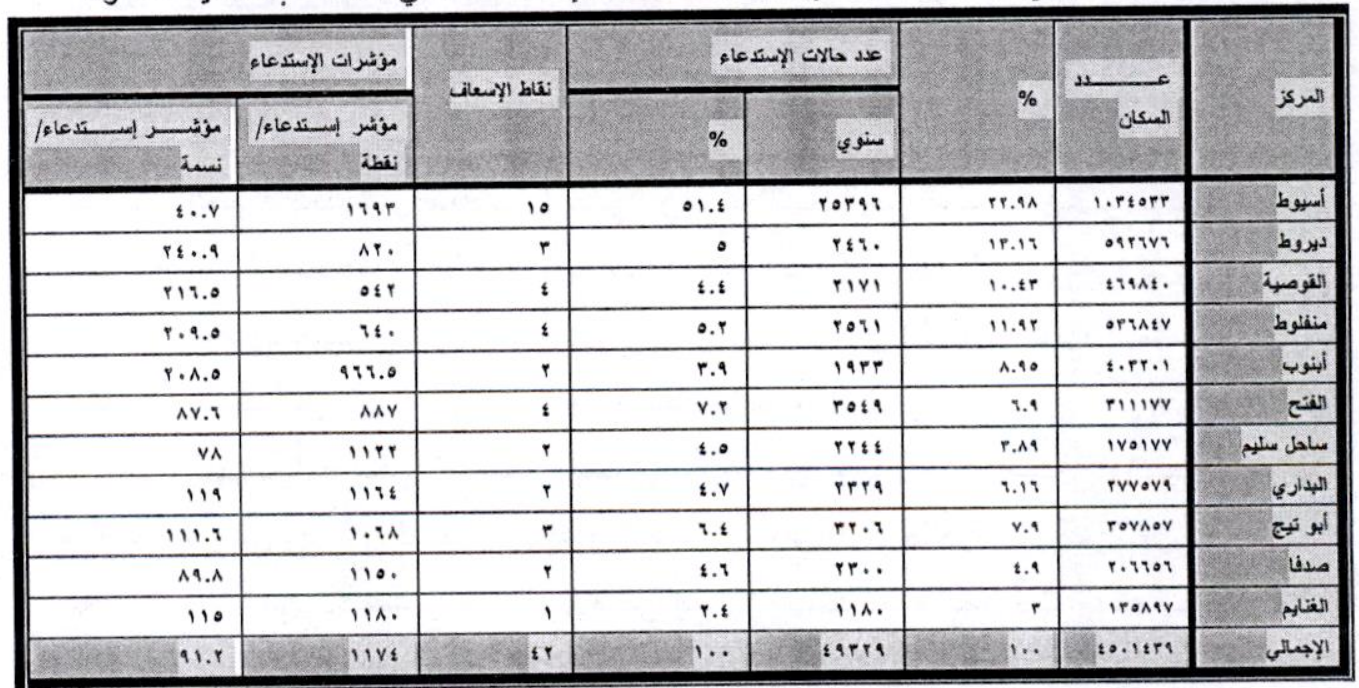

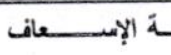

هات

بيات

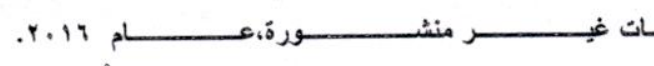

بـان

المص

ـوط بيانس

دول

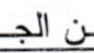

وينض

$\underline{:}$

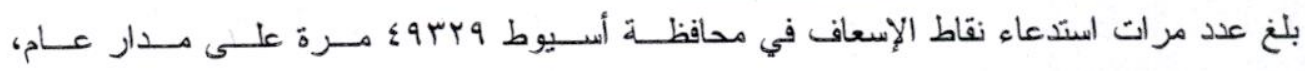

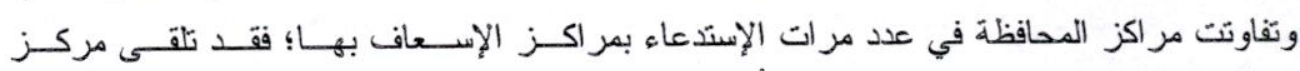




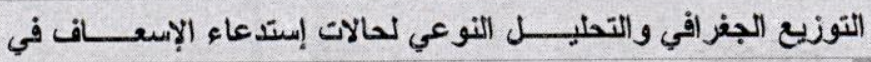

أحمد علي أحمد علي

by

محافظـــــــة أسي

$=\frac{50}{0}$

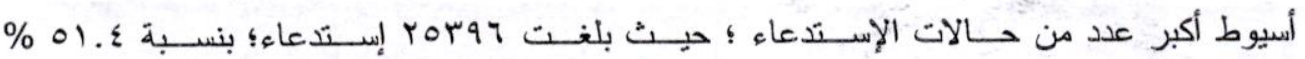

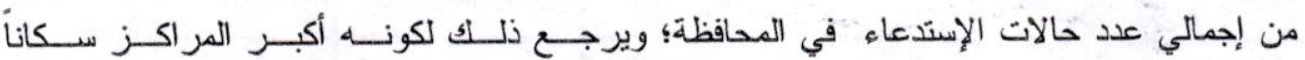

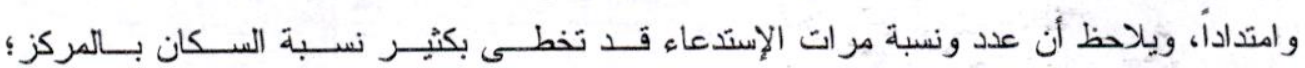

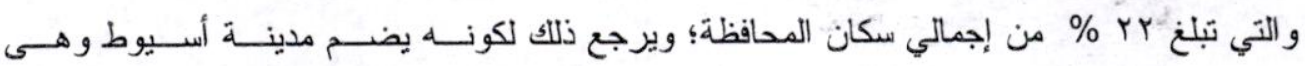
العاصمة الإدارية للمحافظة، والتي تستقطب حركة سكانية من مختلف مر اكز المحافظة.

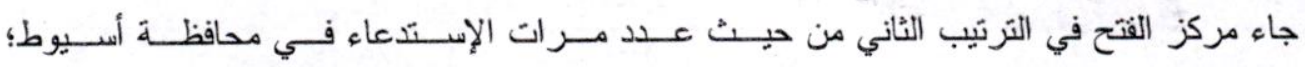

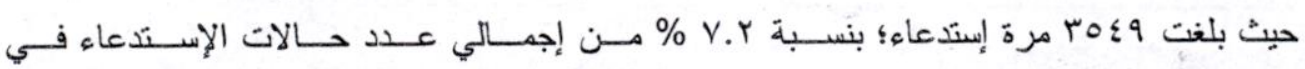

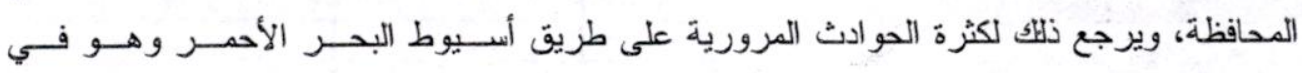
نطاق خدمة نقاط إسعاف مركز الفتح.

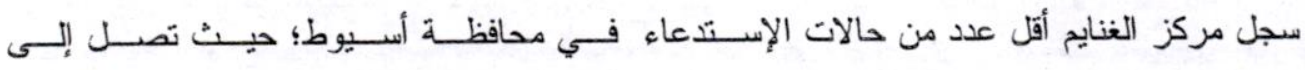

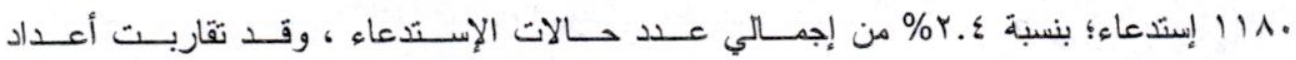

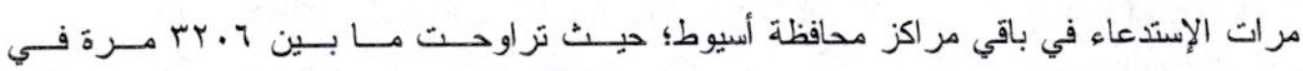

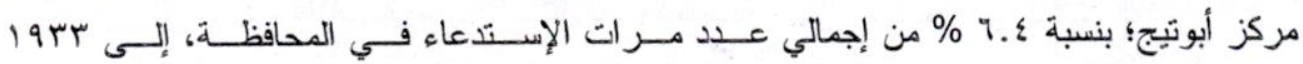

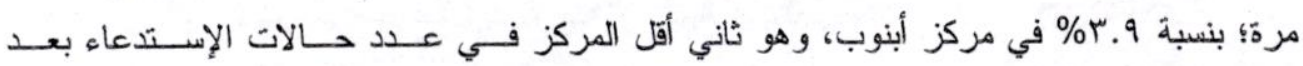
مركز الغنايم. ثالثأ- توزيع حالات الإستدعاء حسب النوع والسن في محافظة أسيوط:

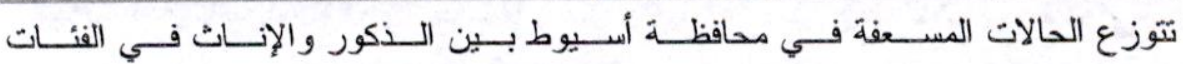

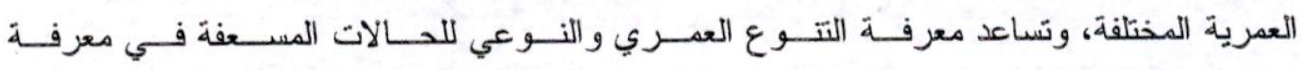

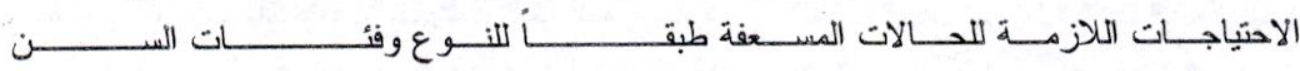
المختلف. ــــــــة. (يدول

توزيع الحالات المسعفة حسب النوع و السن في محافظة أسيوط 


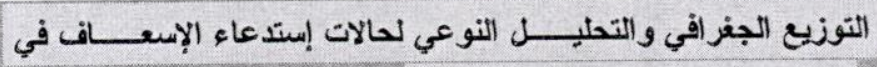

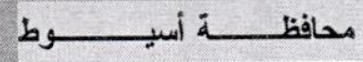

$=\frac{\pi}{6} \mathrm{~s}$

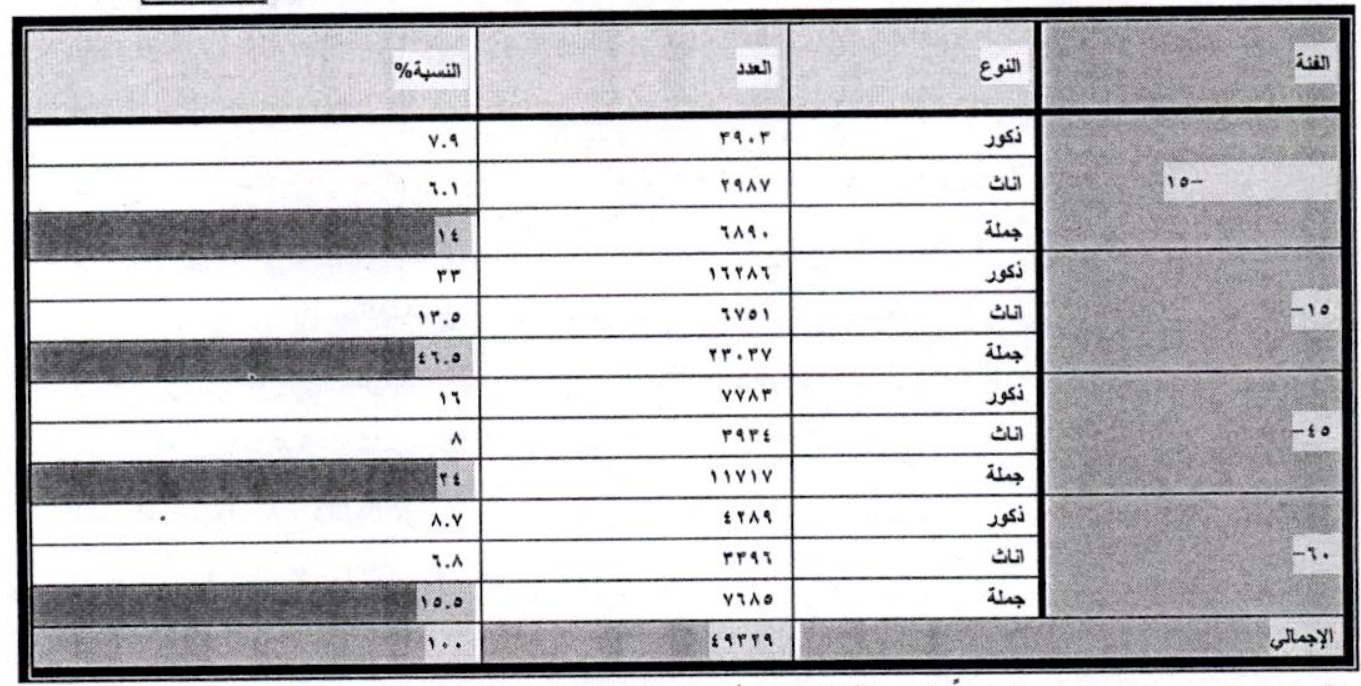

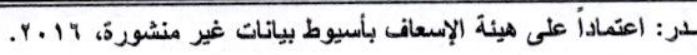

المص

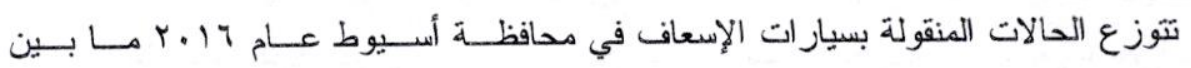

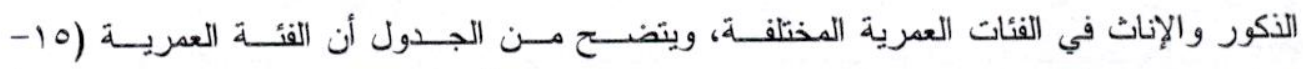

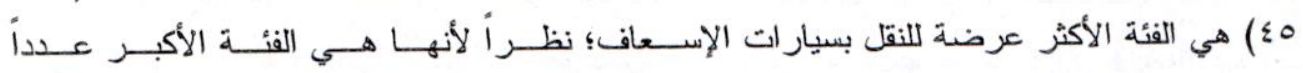

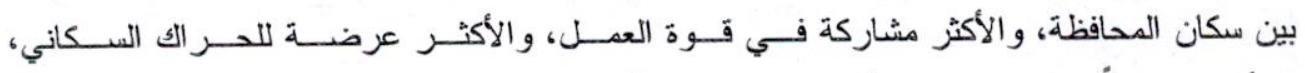

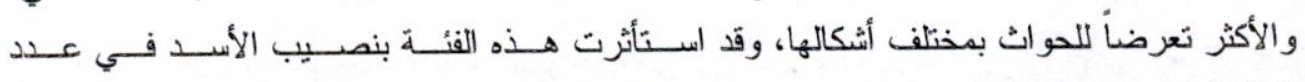

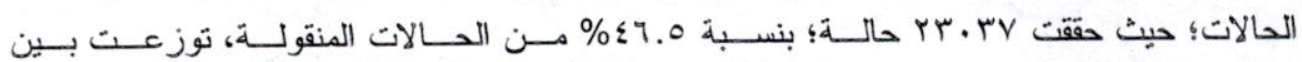

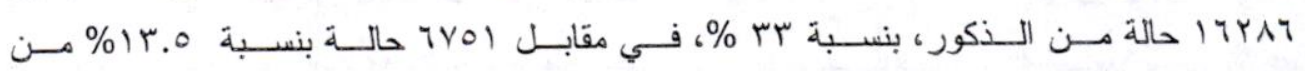

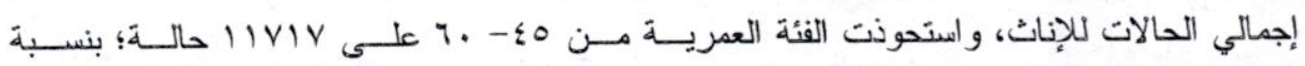

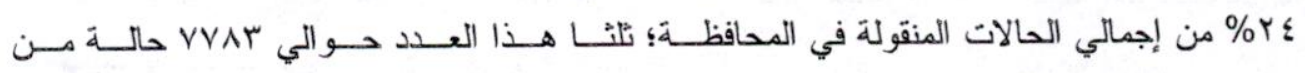

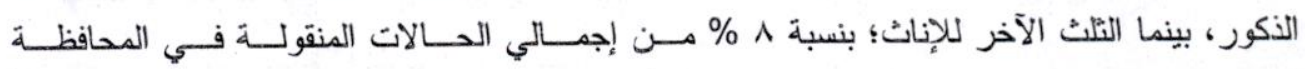

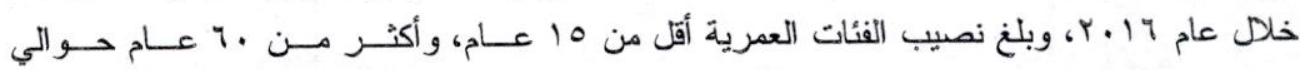

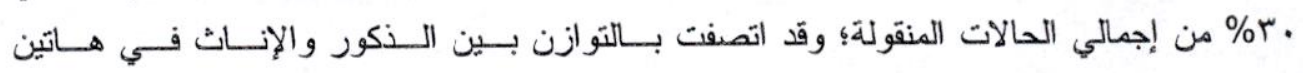




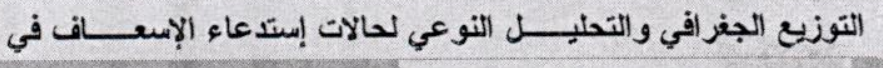

أحمد علي أحمد علي

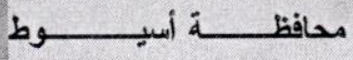

$=\frac{\hat{\sigma}}{\mathrm{G}} \varepsilon \mathrm{V}$

$\sqrt{0}$

رابعأ- توزيع حالات الإستدعاء حسب معدل البقاء على قيد الحياة:

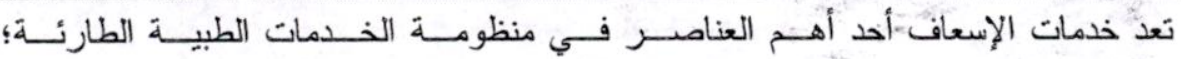

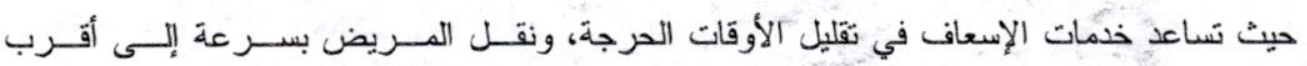

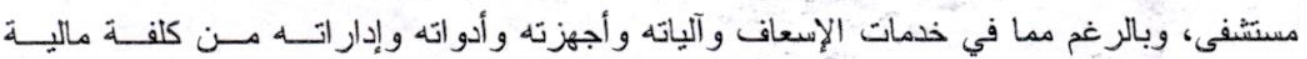

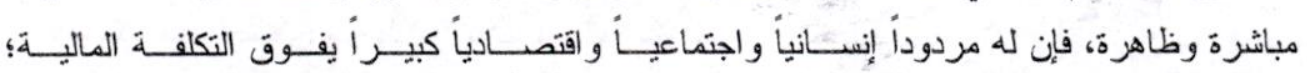

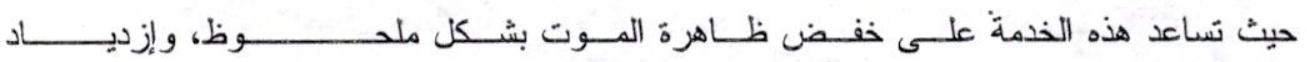

معدل بقاء الفرد المسعف على قيد الحياة (Terzi,D, et al, 2013,P15).

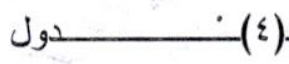

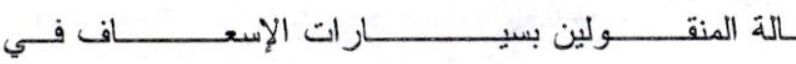

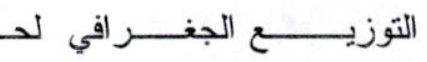

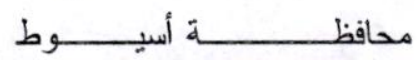

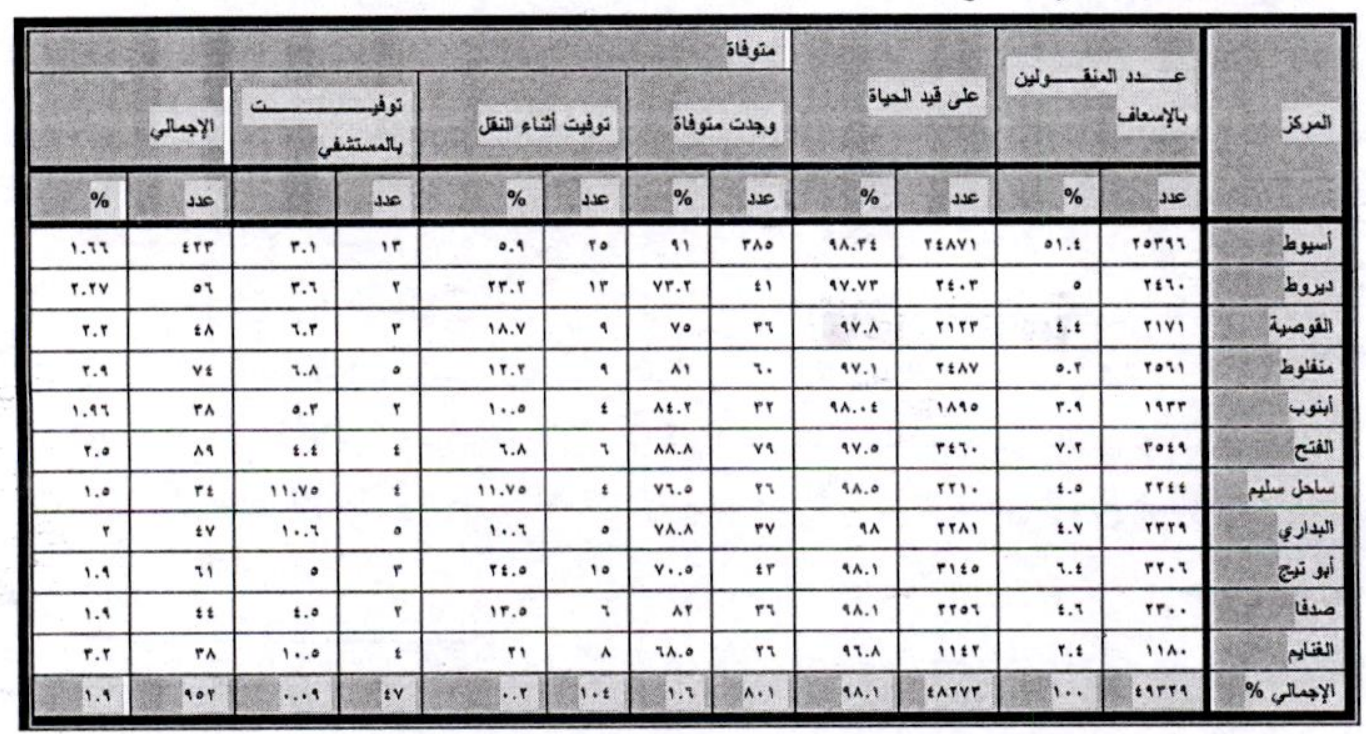

¿

bg

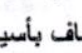

الإسع

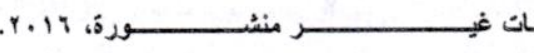

بيانس

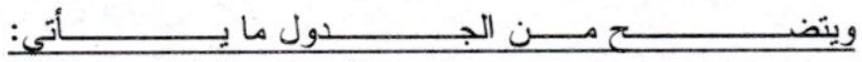




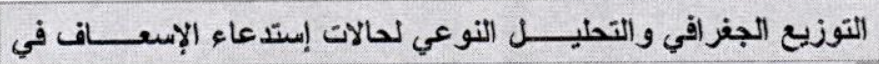
أحمد علي أحمد علي

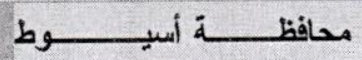

$=\frac{21}{6}$

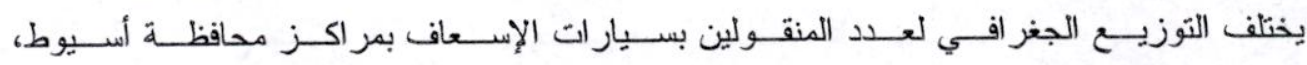

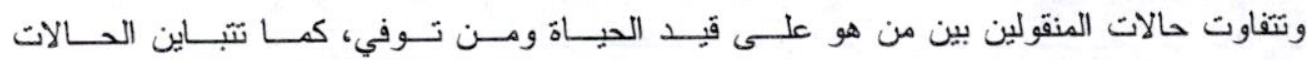

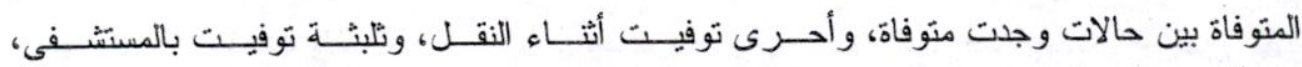

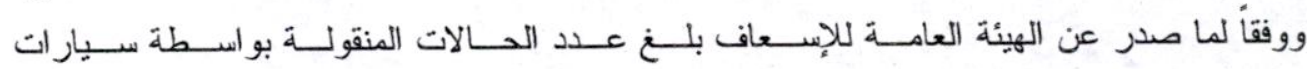

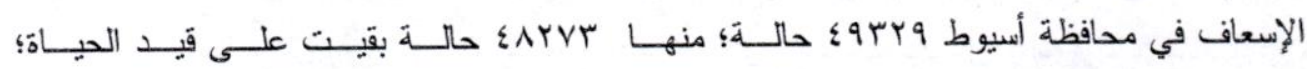

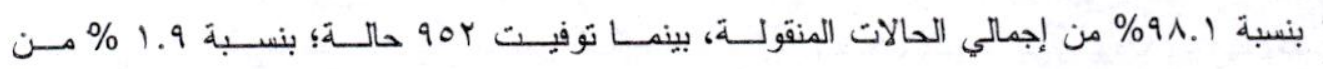

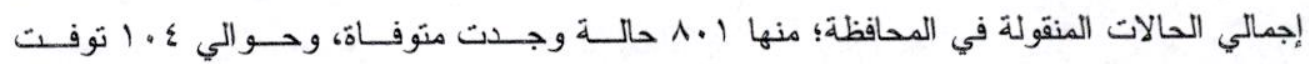

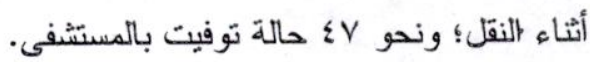

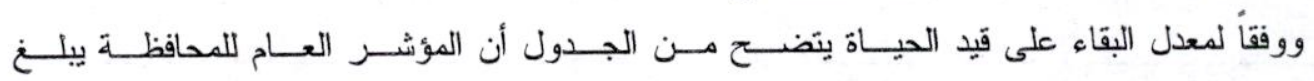

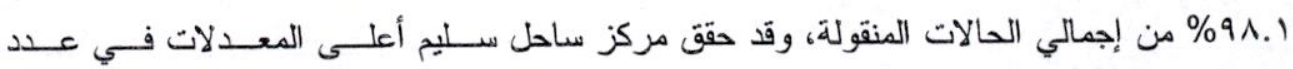

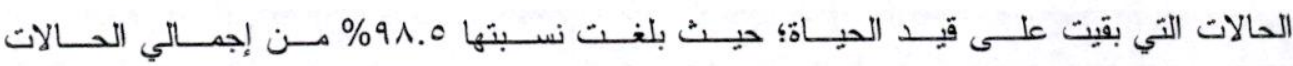

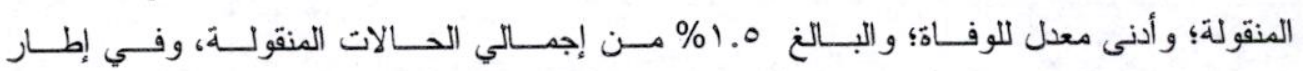
التباين المكاني لهذا المعدل يمكن تقسيم مر اكز المحافظة إلى الفئات الآتية:

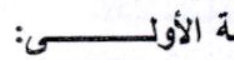
(i)

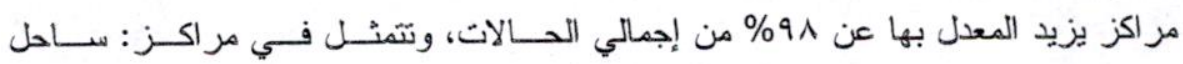

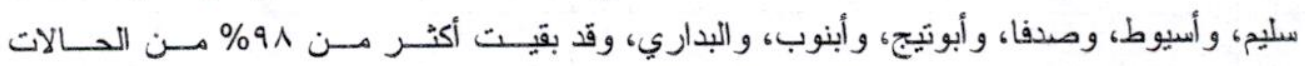

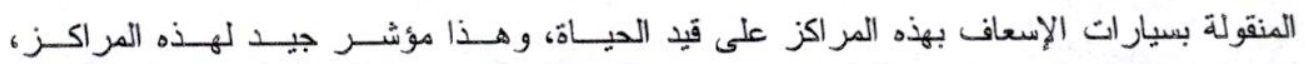

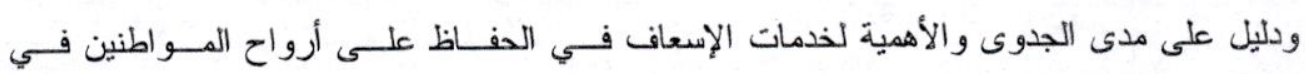
مر اكز محافظة أسيوط.

\section{:} ة الثاتي لي الفئ

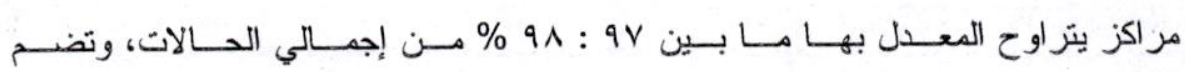

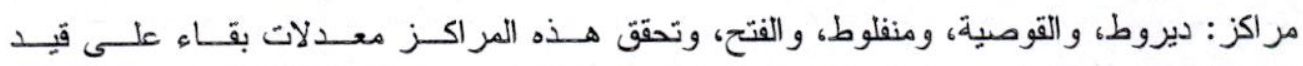

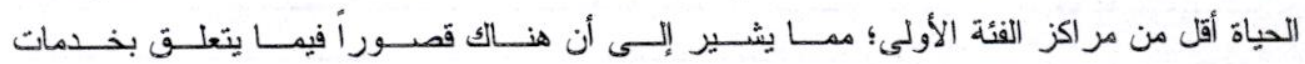
الإسعاف، أو تجهيزات السيارة، أو حالة الطريق. 


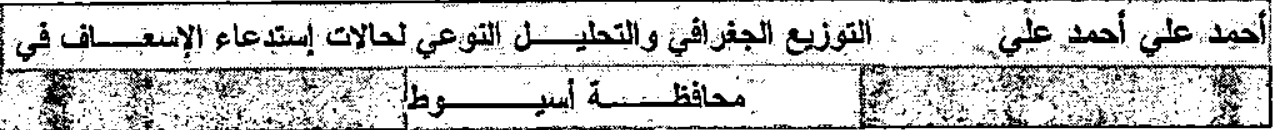

$=$ \%

\%

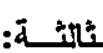

(الفنـ

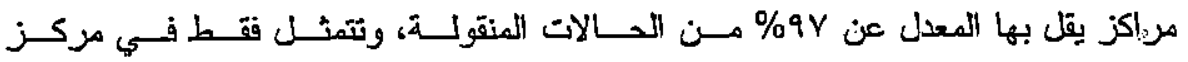

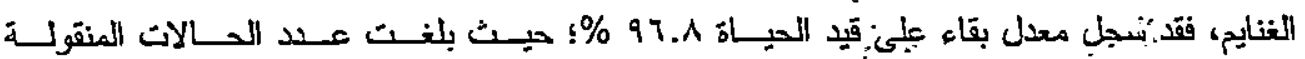

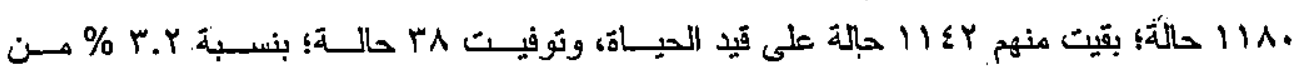

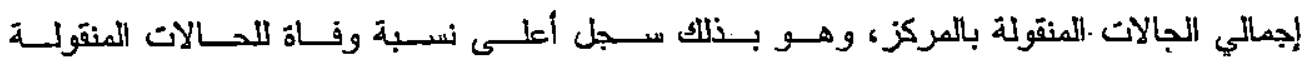

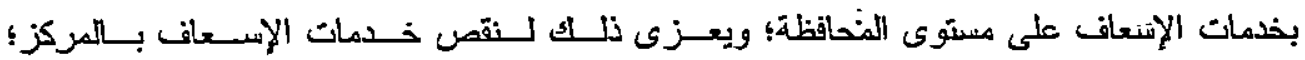
حيث لا توجد سوى نقطة إسعاف واحدة.

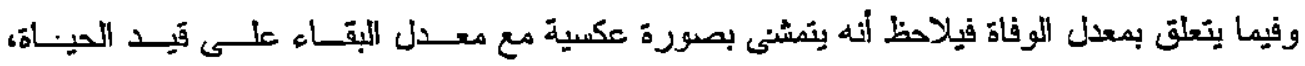

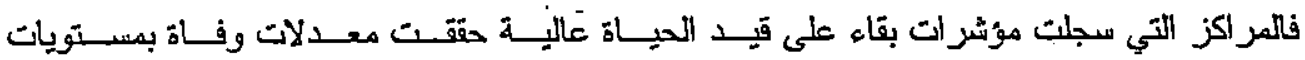

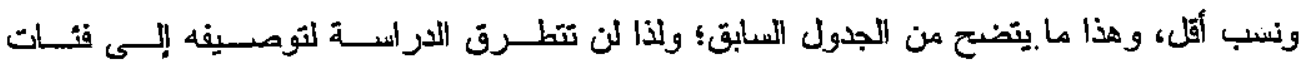

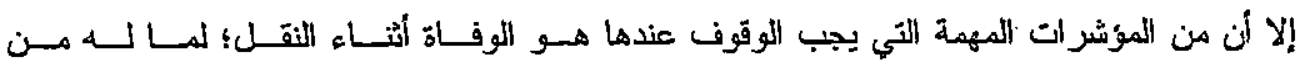
مدلول جغرافي خاصة فيما يتعلق بنهولة الوصول، وسرعة الاستجابة للإستداعاءات.

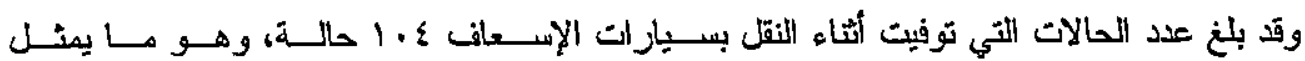

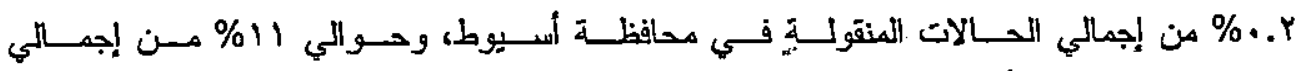

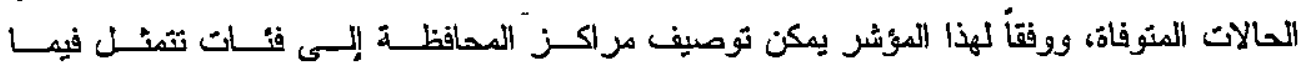
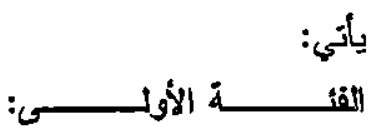
(ํํㄱ

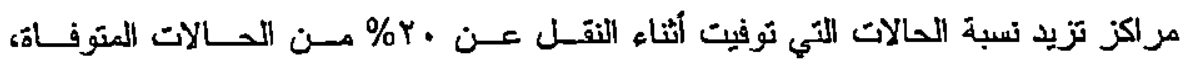

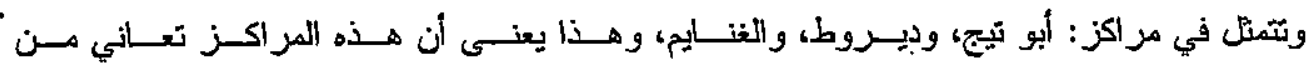

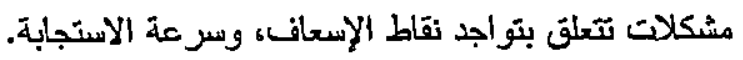
: الثنات الف:

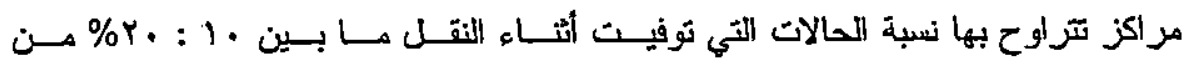

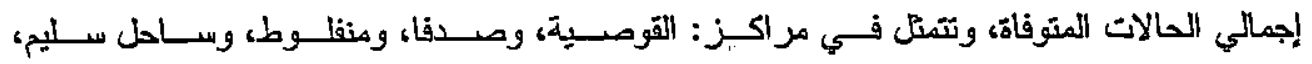

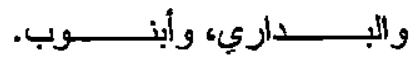




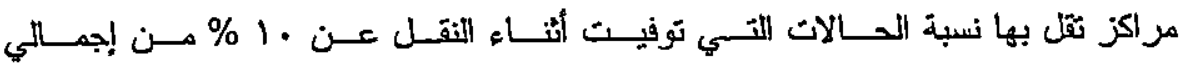

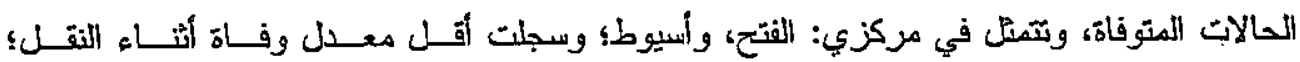

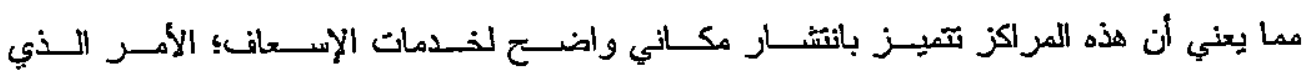

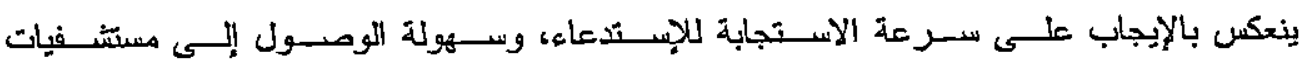
الإخــــــاء.

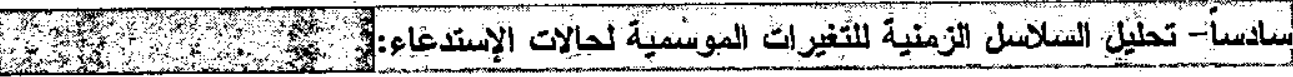

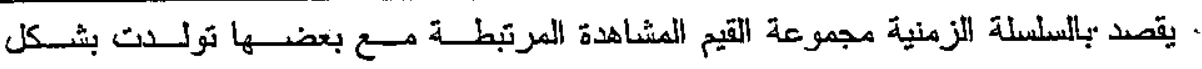

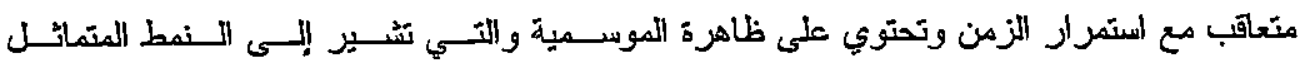

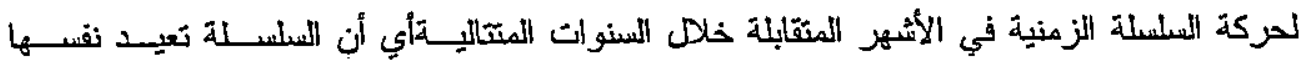
بعد فترات زمنية ثابتة وتدعى هذه الققزة بالفترة الموسمية.

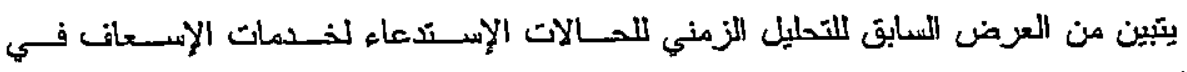

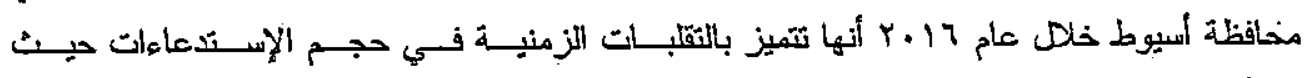

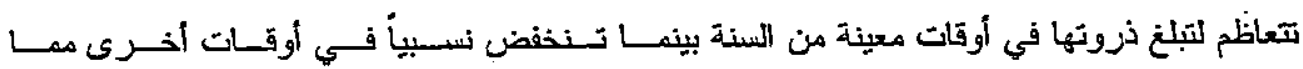

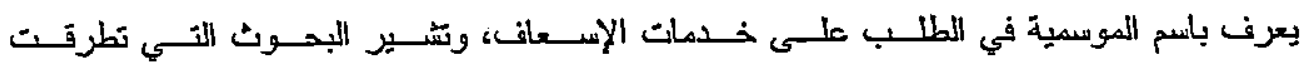

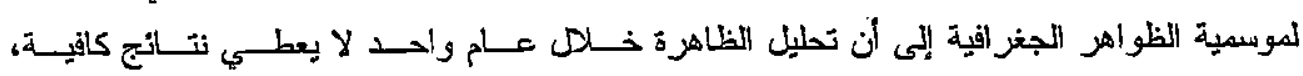

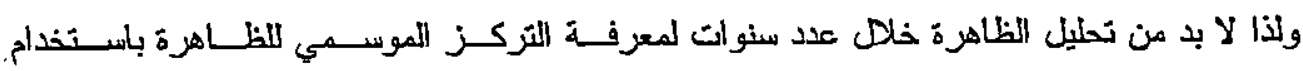

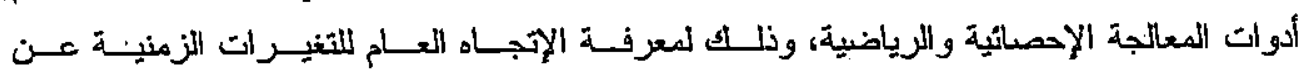
طريث تحليل السلاسل الزمنية للظاهرة. معامل التغيرات الموبسمية:

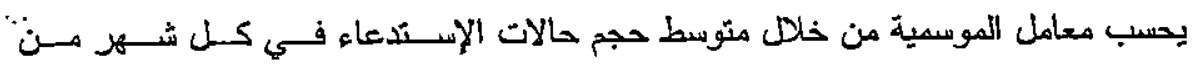

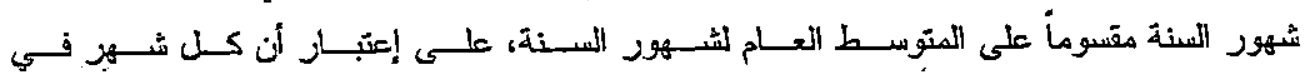

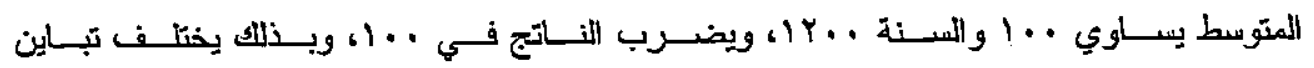

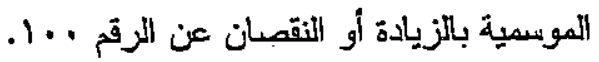




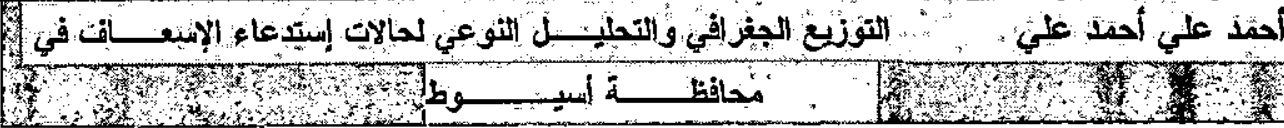
$=0$

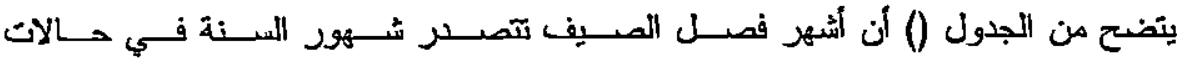

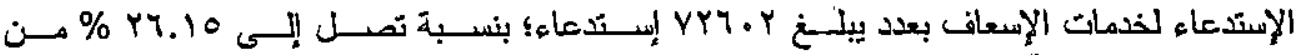

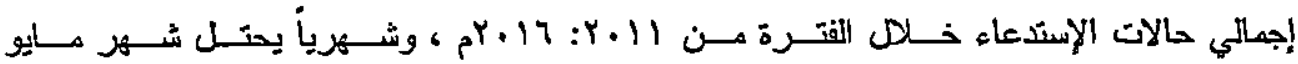

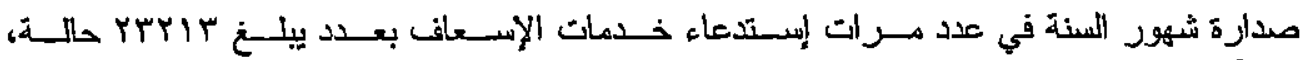

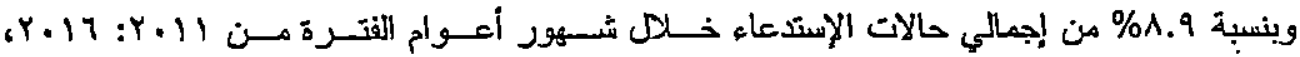

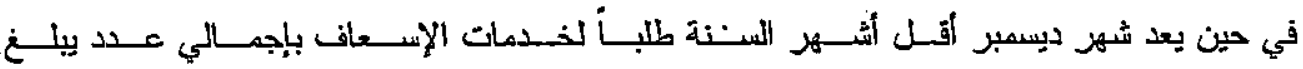

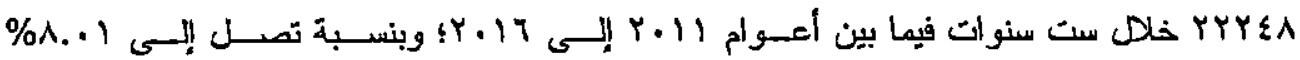
من إجمالي حالات الإستدعاء.

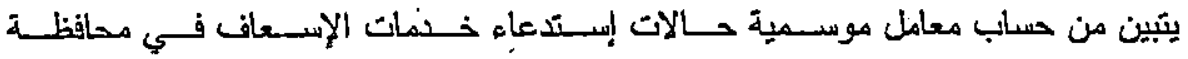

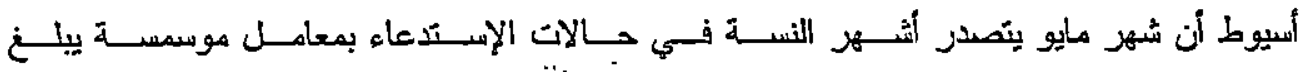

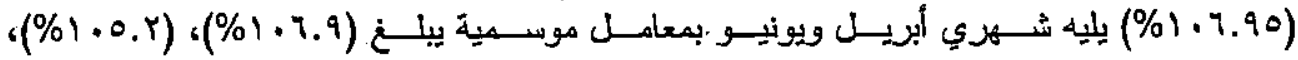

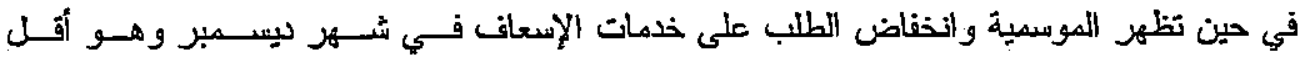

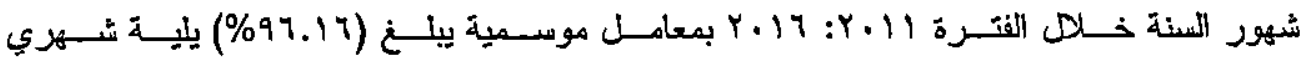

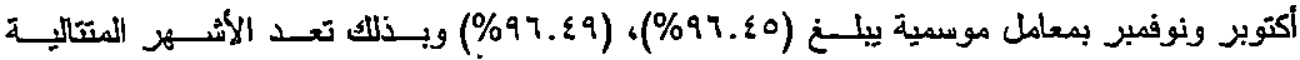
أكتوبر، ونوفمبر، وديسمبر أقل شهور السنة تسجيلا لمعامل الموسمية.

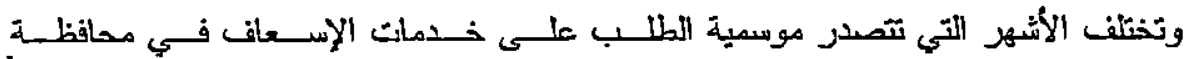

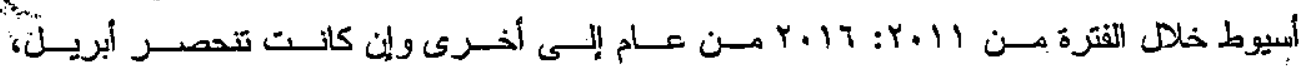

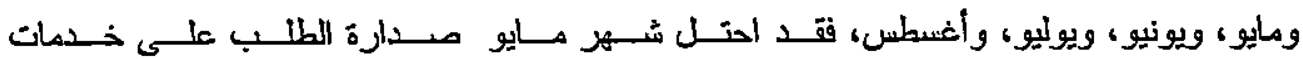

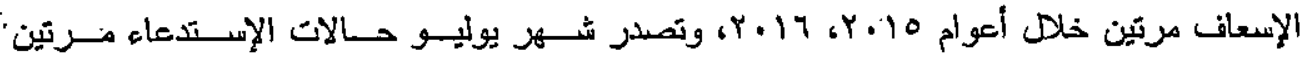

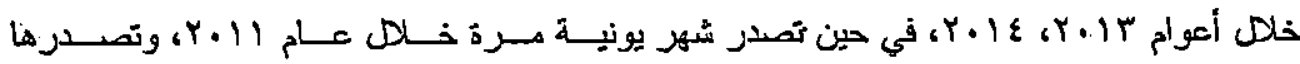

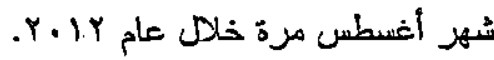
معامل جيني:

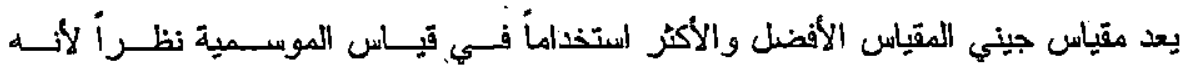

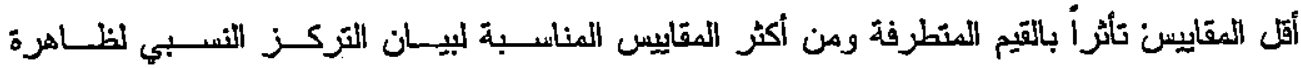




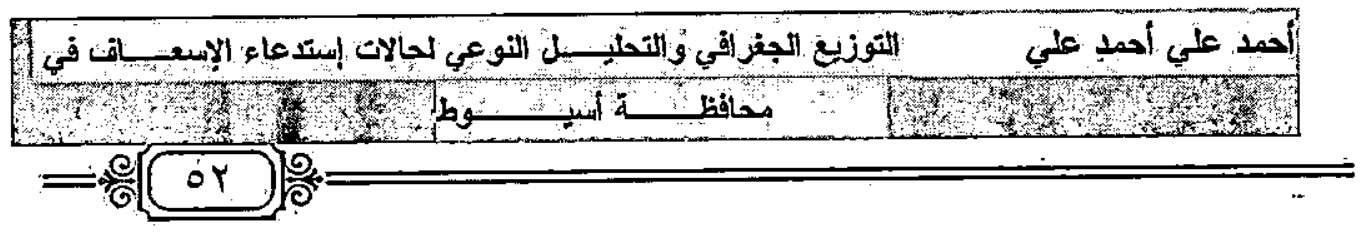

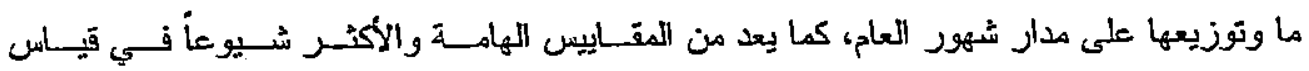

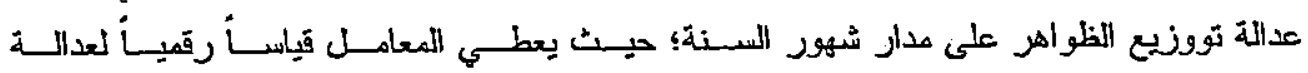
التوزيع،

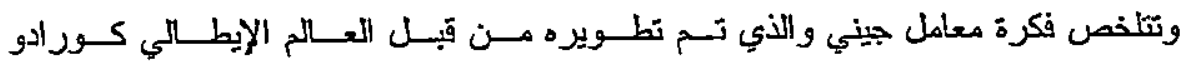

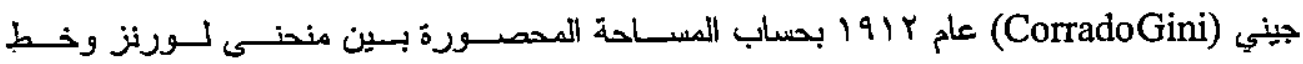

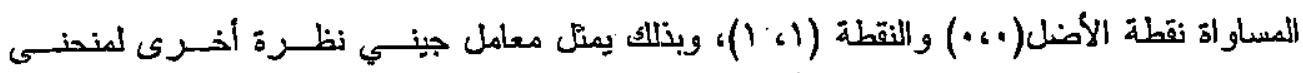

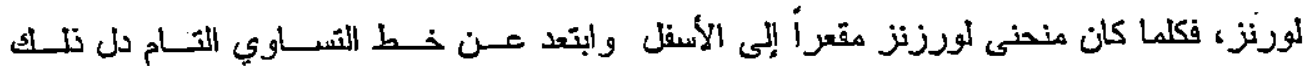

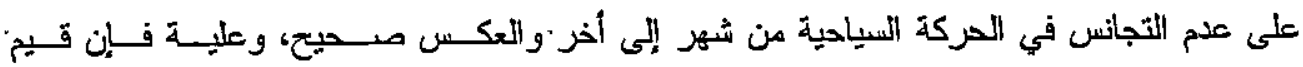

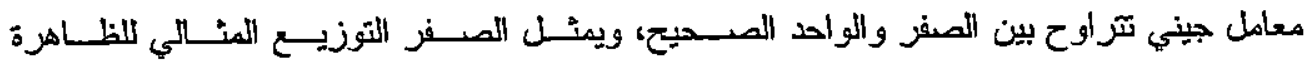

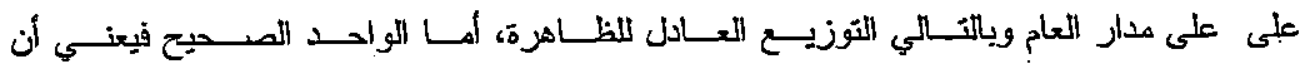
حدوث الظاهزة في شهز واحد في العام وبالتالتي الموسمية التامة.

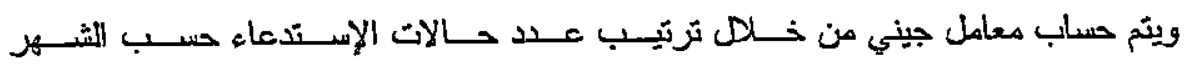

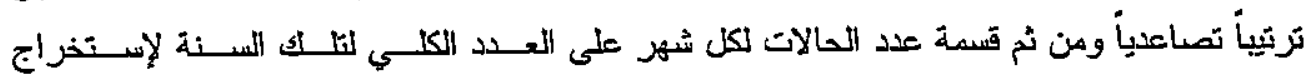

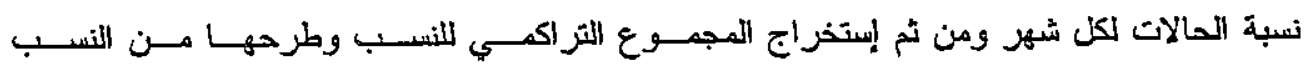

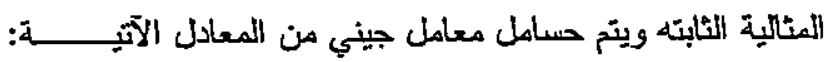

\section{Gini Coefficient $=2 \ln \sum(x i-Y i)$}

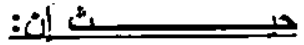 N} -Xi المعادلة (Y/M -Yi حالات الإستدعاء في كل شهر علي إجمالي الحالات في المعام. 


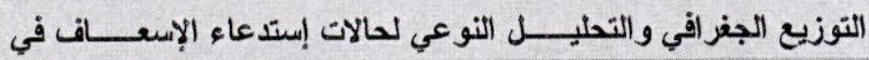

أحمد علي أحمد علي bو محافظ

$=\frac{\mathrm{C}}{\mathrm{O}} \mathrm{Or}$

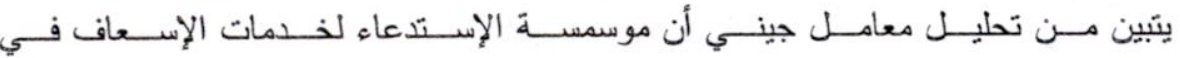

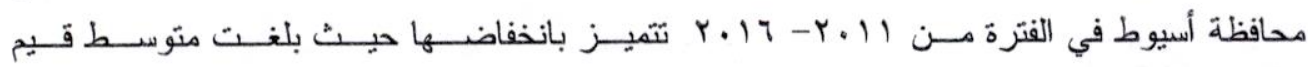

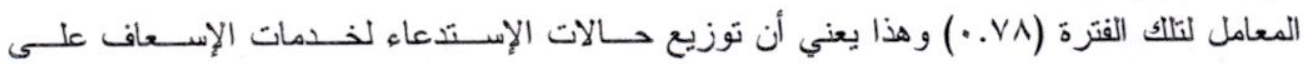

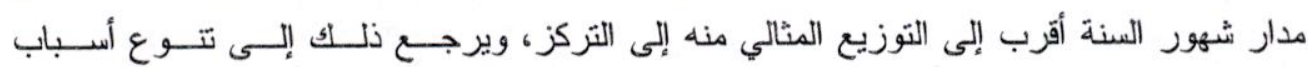
الطلب على خدمات الإسعاف، وقد انضّح ذلك من التحليـلـل النــوعي لخــدمات الإســعاف و التــي توصفها الهيئة إلى ع ا سبب إضافة إلى العديد من الأسباب غير الموصفة.

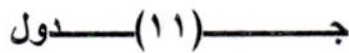

نتانج تطبيق معامل جيني لقياس موسمية حالات إستدعاء خدمات الإسعاف في محافظة أسيوط

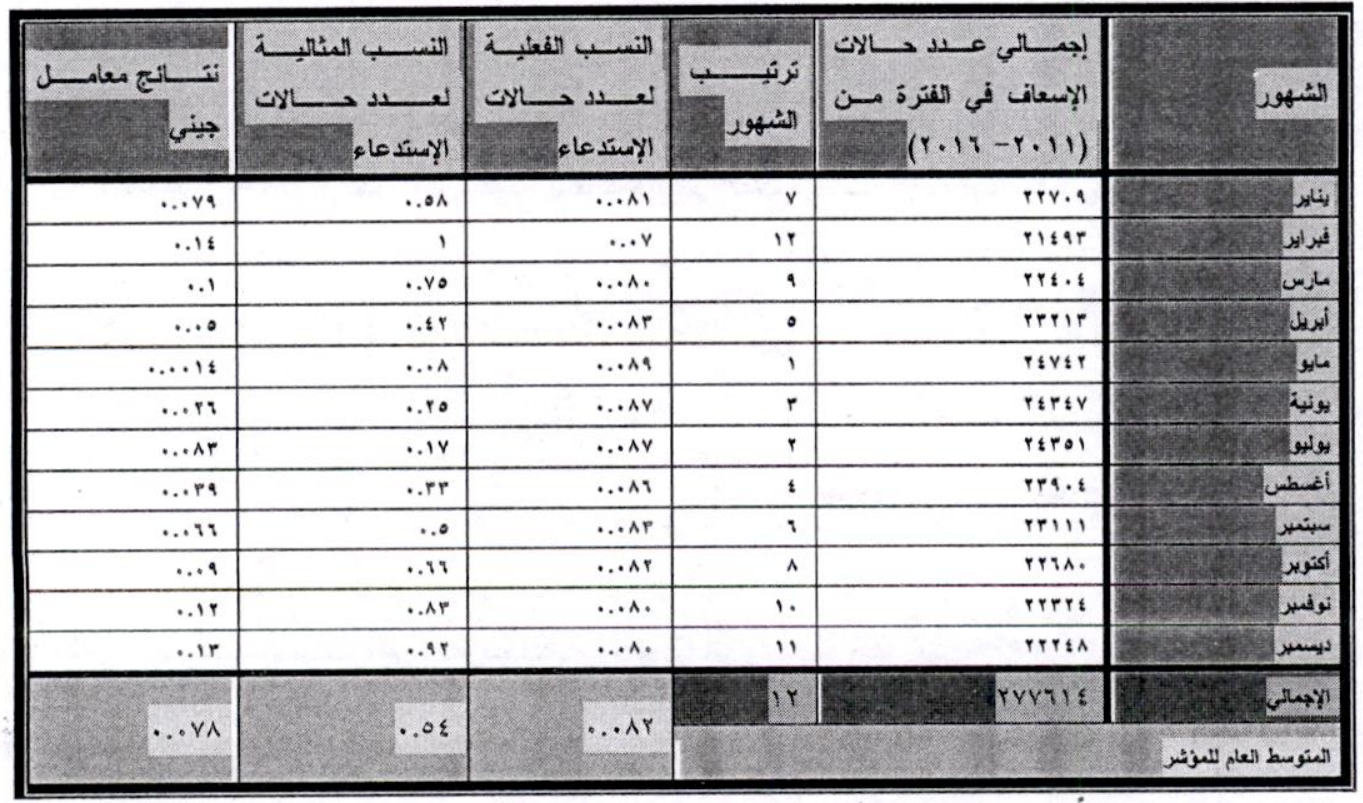

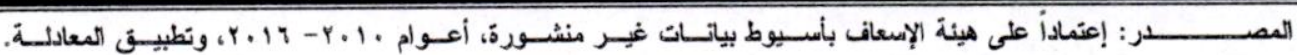




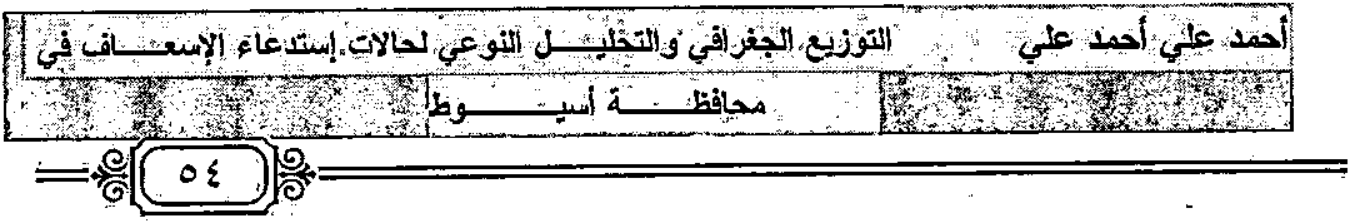

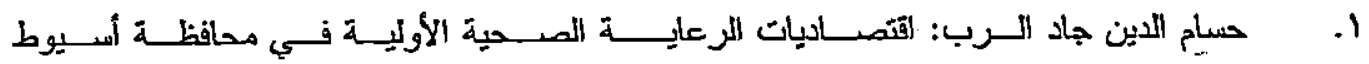

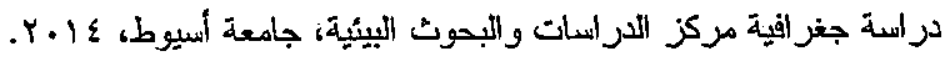

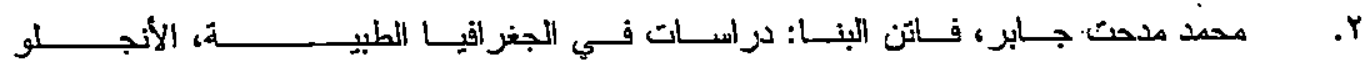

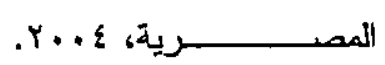

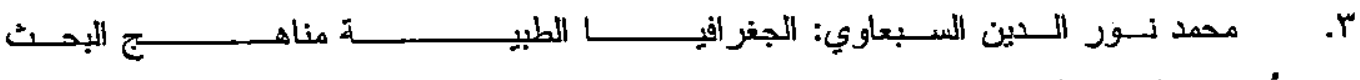

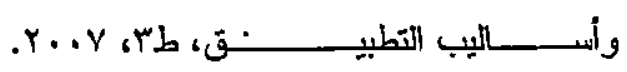

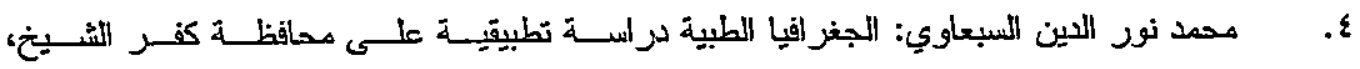

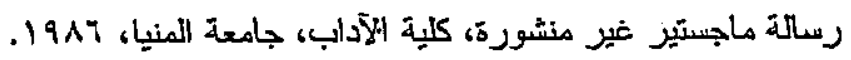

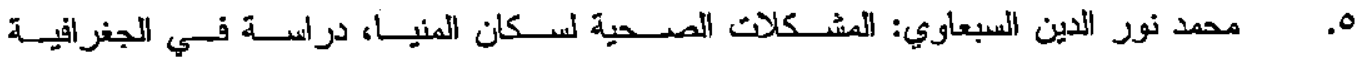

الطبيية، رسالمة دكتوراه غير منشوزة، كلية الآداب، جامعة المنيا،ب99 19.

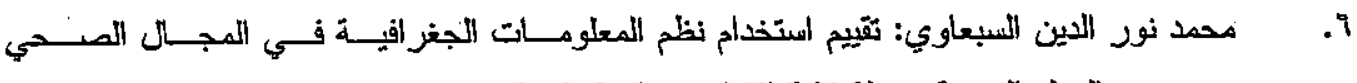

بمحسر وبعض الأول العربية، مجلة كلية الاداب، جامعة المنيا ،9. . . . .

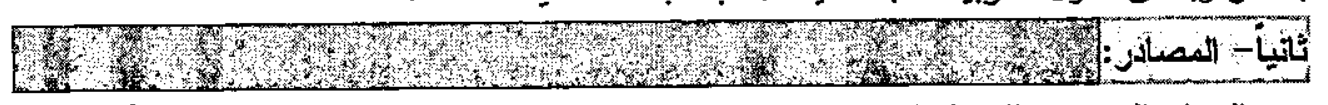

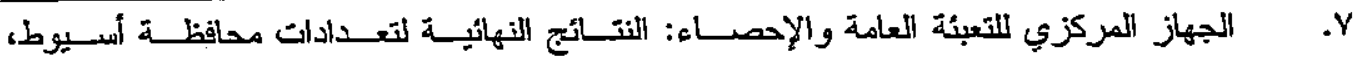

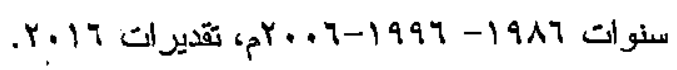

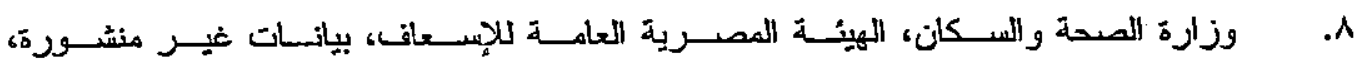

. Y. 17

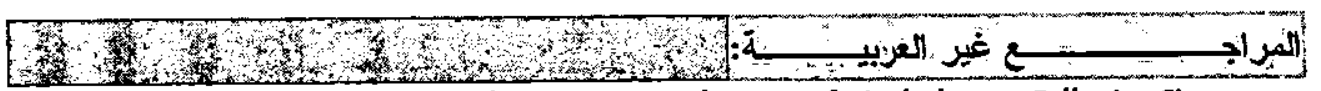

1. Marcus, O, et al," "Geographic-Time Distribution of Ambulance Calls in Singapore:

. Utility of Geographic Information System in Ambulance Deployment" International Journal of Health Geographic, 2008.

2. Meyer, E., Performing Location Allocation Measures with A Gis for Fire Stations in Toledo, Ohio". Theses and Dissertations, The University of Toledo, P15: paper 644. 2011. 
3. Patel,B, et al, " A validation of ground ambulance pre-hospital times modeled using geographic information systems", International Journal of Health Geographic, 2012.

4. Terzi,O, et al, " A geographic information system-based analysis of ambulance station coverage area in Samsun, Turkey" International Journal of Health Gẹgraphic ,2013.

5. Christophor,P, "Analysis of Emergency Medical Systems Across the World" International Journal of Health Geographic, 2013.

.6. Rachel, H, et al, "Health Services and Delivery Research, International Journal of Health Geographic 2014.

7. David, P, et al, "'Modeling the cost of providing ambulance services", International Journal of Health Geographic 2014.

8. 